\title{
HVDC Grid Segmentation Analysis for Blackouts Reduction
}

\section{Grazielle Jacinta Cardoso Santos, Patrícia Romeiro da Silva Jota}

Electrical Engineer Department, Federal Centre of Technological Education (CEFET-MG), Belo Horizonte, Brazil

Email: graziellejsantos@gmail.com,prsjota@dppg.cefetmg.br

How to cite this paper: Santos, G.J.C. and da Silva Jota, P.R. (2017) HVDC Grid Segmentation Analysis for Blackouts Reduction. Journal of Power and Energy Engineering, 5, 36-48.

https://doi.org/10.4236/jpee.2017.53003

Received: February 3, 2017

Accepted: March 27, 2017

Published: March 30, 2017

Copyright $\odot 2017$ by authors and Scientific Research Publishing Inc. This work is licensed under the Creative Commons Attribution International License (CC BY 4.0).

http://creativecommons.org/licenses/by/4.0/ (c) (i) Open Access

\begin{abstract}
Segmentation of large AC systems through DC links introduces a new concept that utilizes the advantages of direct current transmission to improve network reliability and increase power transfer capacity. Technical literature argues that the segmentation of the AC network and the introduction of DC links at these systems connection points bring benefits to system operation, once contingencies generated on one side of the DC connection point would not be reflected on the other side of DC connection, thereby reducing the likelihood of cascading shutdowns and blackouts due to load restraint on transmission lines and transformers. Amidst this scenario, this paper presents a study of the main topics regarding the use of this new network segmentation philosophy, bringing a practical point of view for the use of this concept at the electrical power system planning. The effect of DC segmentation before a contingency that would initiate major outages in an adapted electrical system model IEEE-14 bus is studied and simulations have been performed with test HVAC systems and segmented by HVDC link. The results have been compared, principally in relation to the voltage bus, reactive power generation, system losses and power flow at the lines, and demonstrated that this new concept improved the grid reliability.
\end{abstract}

\section{Keywords}

DC-Segmentation, Grid Segmentation, DC Link, Blackouts, Cascading Outages

\section{Introduction}

The power transmission networks are complex systems that have experienced blackouts at last recent decades. These events raise concerns about the stability and safety of the electrical system operation. Currently, the AC technology's ability to adapt and ensure grid security and manage the growth of demand for 
transmission services is being questioned [1] [2].

The high-voltage technology in direct current (HVDC) has characteristics that make active hereinbefore for certain applications. The HVDC transmission is widely recognized for delivery large blocks of energy over long distances, asynchronous interconnection and for energy transmission by submarine cables. The actual number of HVDC projects under consideration or in application around the world has increased at last years, reflecting a renewed interest in this technology [3] [4].

Compared with the three-phase AC system, HVDC is higher in follow aspects: less constructive and operating cost, allows asynchronous interconnection between two AC systems and is easy to control and to adjust power flow. Nowadays, the level of confiability of HVDC link must be greater than double AC line utilization [3] [4] [5].

The large AC networks segmentation through DC links introduces a new concept that retains the advantage of the two technologies to improve network reliability. According to Mousavi et al. [1], segmentation is defined as the use of DC links to split large AC networks into sets of a smaller asynchronously operated AC segments. HVDC technology, in addition to the AC transmission system, could mean an increase in reliability, energy transfer capability and security of electric power system operation. Figure 1 shows the DC segmentation concept of a large AC system into several smaller AC segments interconnected only by DC bonds.

The segmentation of large networks AC through DC bonds has the advantage that problems in one of the new AC segments are not transferred to the next AC segments, in addition, DC link can be controlled. Under contingency conditions, differently of AC lines, DC bonds would not be overloaded due to controllability of power flow, which significantly reduces the risk of cascade interruptions [1] [6].

Cascade interruptions can occur immediately following a contingency due to loss of a transmission line or a fault that initiates a rapid voltage collapse. These

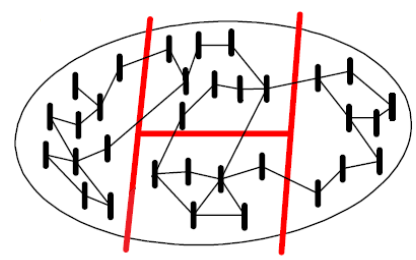

(a)

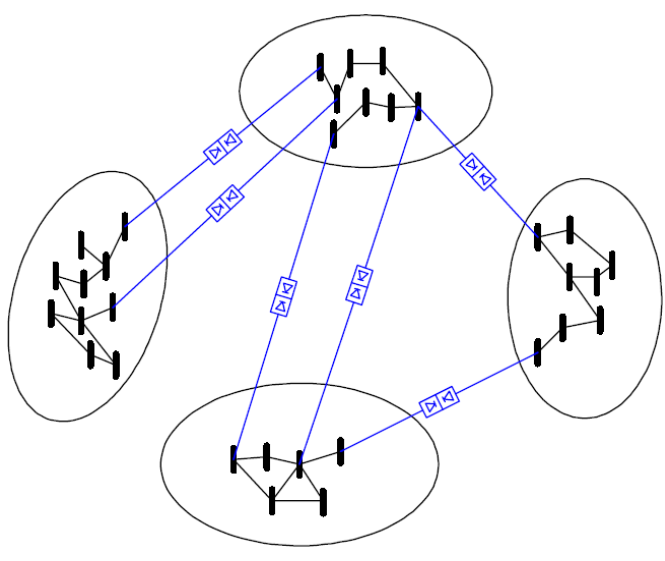

(b)

Figure 1. The electrical system DC-segmentation contains: (a) CA system division into segments (b) reconnection of the segments through the DC links. Adapted from [1]. 
causes may not be a significant problem, but with the interconnected power grid and increase of AC line overload, such contingencies will increase the threats of cascading interruptions. Contingencies occur sequentially and are aggravated by operating errors, downtime, system imperfections or failures [7].

\section{Grid Segmentation}

In [2], the DC segmentation hypothesis is defined as the decomposition of any interregional $\mathrm{AC}$ network in a set of sectors asynchronously operated and interconnected by DC links in order to achieve the following improvements in a viable and profitable way:

- Minimize cascading interruptions;

- Increase the capacity of energy transfer between sectors;

- Solve interconnection issues;

- Strengthen local oversight of regional networks.

Segmentation works by controlling the power flow across the boundaries of the HVDC. At its simplest form, each converter station is tuned to a specific power level and a maximum power level that is agreed between the operators of adjacent sectors. Under normal conditions, the power levels change only under the control of the operators. When a disturbance occurs, controller on each back to back station and each HVDC line increase the power flow from the system with higher frequency difference, up to the set maximum [7].

Without segmentation, the entire interconnection operates on the uniform frequency of the AC network, subjecting it to the consequences of the network response to each contingency. This network response, can sometimes, exceed the limits of angular stability and presents voltage with catastrophic results. With DC links utilization it is allowed that the frequency of each sector, under a contingency, has a behavior to the disturbance within the sector itself. Considering Figure 2, the loss of a generator will result in a drop of frequency within the sector $\mathrm{A}$ and will cause a response from the generation of this sector itself. The generation of neighboring sectors, $\mathrm{C}$ and $\mathrm{B}$, will only respond for a support through the DC links. This support is limited, so this does not affect security and stability in assistants sectors. Thus, when the load in sector A is greater than the demand provided by the DC links plus its own generation, the sector will be shut down by underfrequency. The disconnection of the sector by underfrequency is a mechanism to avoid the collapse of the entire system [2] [7].

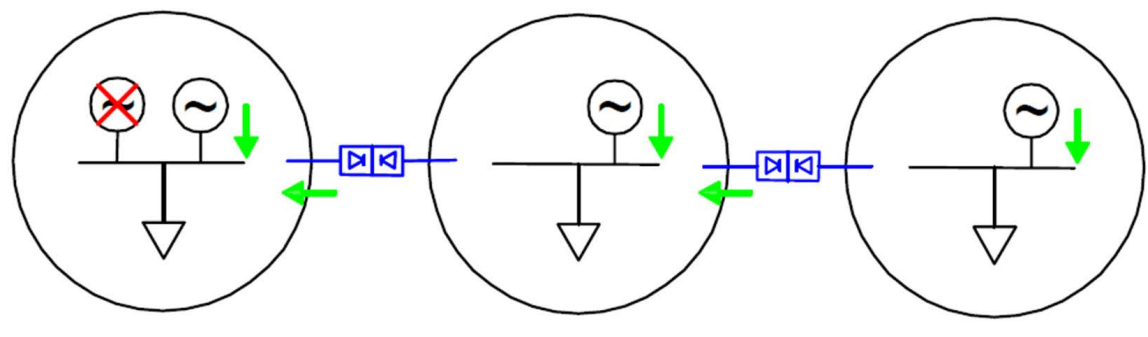

(a)

(b)

(c)

Figure 2. Response of DC links to the disorders. Adapted from [2]. 
AC links do not have mechanisms to maintain power flow within angular stability and voltage limits. In AC systems, large disturbances can impose a high power flow over large areas. This power flow may exceed the capacity of the system and thus initiate a cascade interruption, particularly when aggravated by system imperfections. These problems are solved by segmentation in which HVDC links between sectors avoid instability and maintains regional flows with knowledge of the reactive power and thermal limits of transmission lines [7].

For a segmented network, the worst post-fault scenario is the loss of a complete sector. The power flow limits set in the DC links prevent the power flowing to a failing sector from reaching levels that are hazardous to the neighboring sector. Thus the collapse of one sector leaves the neighboring sectors and the remaining network undamaged. Underfrequency shutdown of a sector is a small price to pay to avoid angular instability or a voltage collapse [2] [7].

\section{Testing Systems}

\subsection{HVAC Testing System}

The test system adopted in this paper is based on IEEE 14 bus. Some adaptations were made to make possible to evaluate the impacts of installing an HVDC link. The system was divided into two areas 1 and 2, as shown in Figure 3 and was connected by two interconnection lines.

The division of the system concentrated the generation in the area 1 and both areas must own generation. To solve this problem, bus 2 , who belongs to area 1 , was transformed into PQ bus with its generator transferred to bus 14 , contained in area 2 . The generation and loading values of the areas were stipulated for the load in area 2 be greater than the generation of bus 14 . Consequently, area 2 demands energy from area 1.

The lines between the buses 2 - 3 and 4 - 5, called interconnection lines, allow the power flow between the areas. The stream will be limited to a single line that

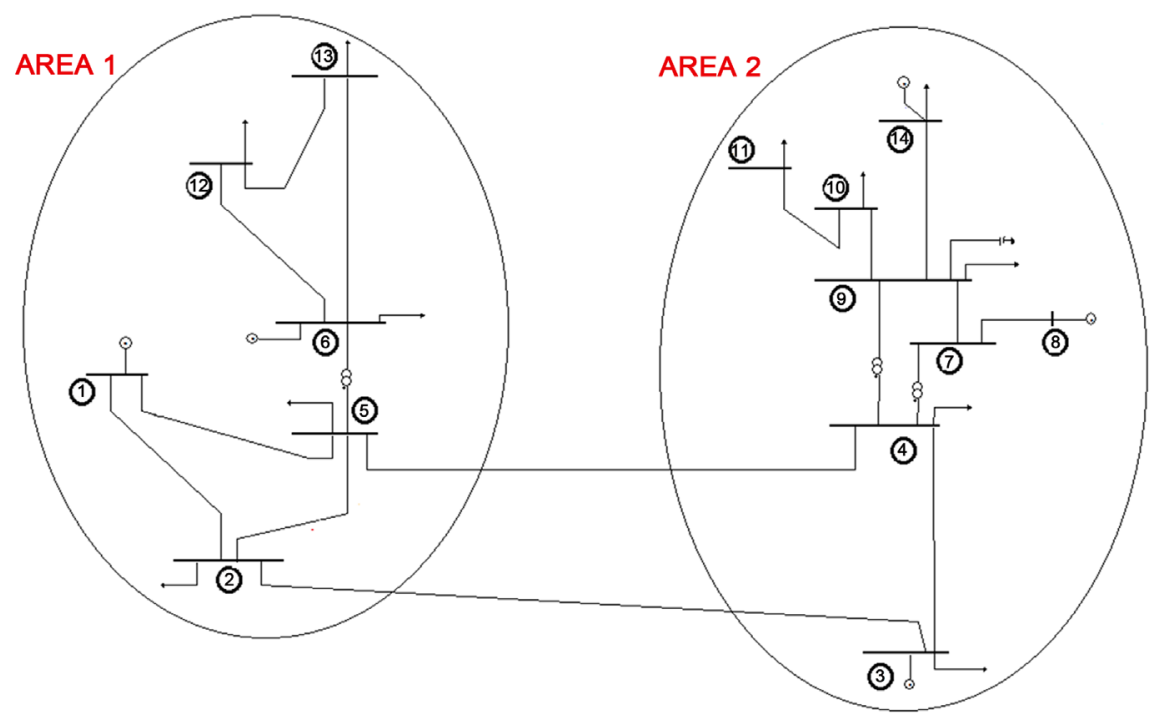

Figure 3. HVAC system. 
will later be replaced by the HVDC link. The most charged line is line $4-5$, chosen to focus power flow between areas. In the system that will be presented below, line 4 - 5 will be replaced by the DC link. In order to simulate this system, it was necessary to create a line connecting the two areas in AC, since the ANAREDE program understands that the DC link isolates the electric network from area 2 leaving it without a reference bus, which is contained in area 1. Therefore, line 2 - 3 was created and adjusted with high resistance value and reactance to mitigate the power flow through it and serve only as $\mathrm{AC}$ connection and to enable calculation of the power flows. In the HVAC test system, this line will also exist in order to maintain the two similar cases for comparison of results.

\subsection{HVAC Segmented by HVDC Link Testing System}

To test the HVAC system segmented for HVDC link, it is used the test HVAC system model and replaced line $4-5$, which connects the two areas, to the HVDC link, as shown in Figure 4. All features of the HVAC test system are maintained for comparison of results between systems.

\section{Simulation and Results}

\subsection{Comparison between Testing Systems}

The HVAC system test and HVAC segmented by HVDC link, despite having the same input data, operate differently due to the operation of the DC link. After insertion of the HVDC link, the modulus and angle of the system voltages were changed, that is, a power distribution of the system has changed. Table 1 and Figure 5 presents the results found.

Table 1 shows the module and angle of the operating voltages of both test systems. The active power flow of the HVAC system is determined by the phasor that is at an advance, in other words, bus that have larger angles to the bus that has smaller angles. Considering the adopted system, the area 2 does not have a reference bus thus, the voltage reference of the bus are made by the intercom-

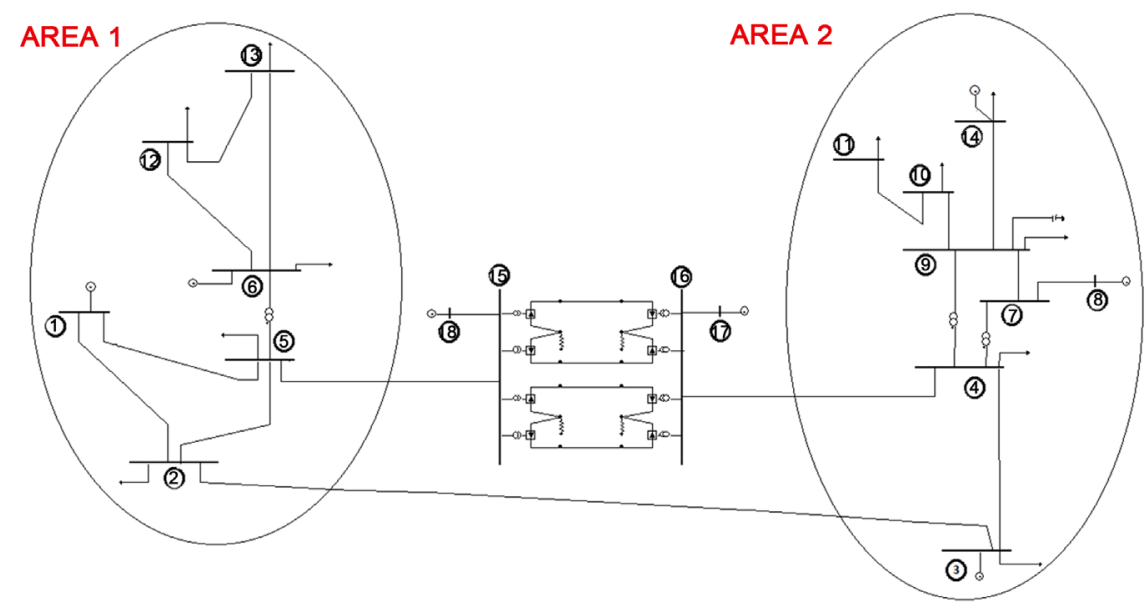

Figure 4. HVAC segmented by HVDC link system. 


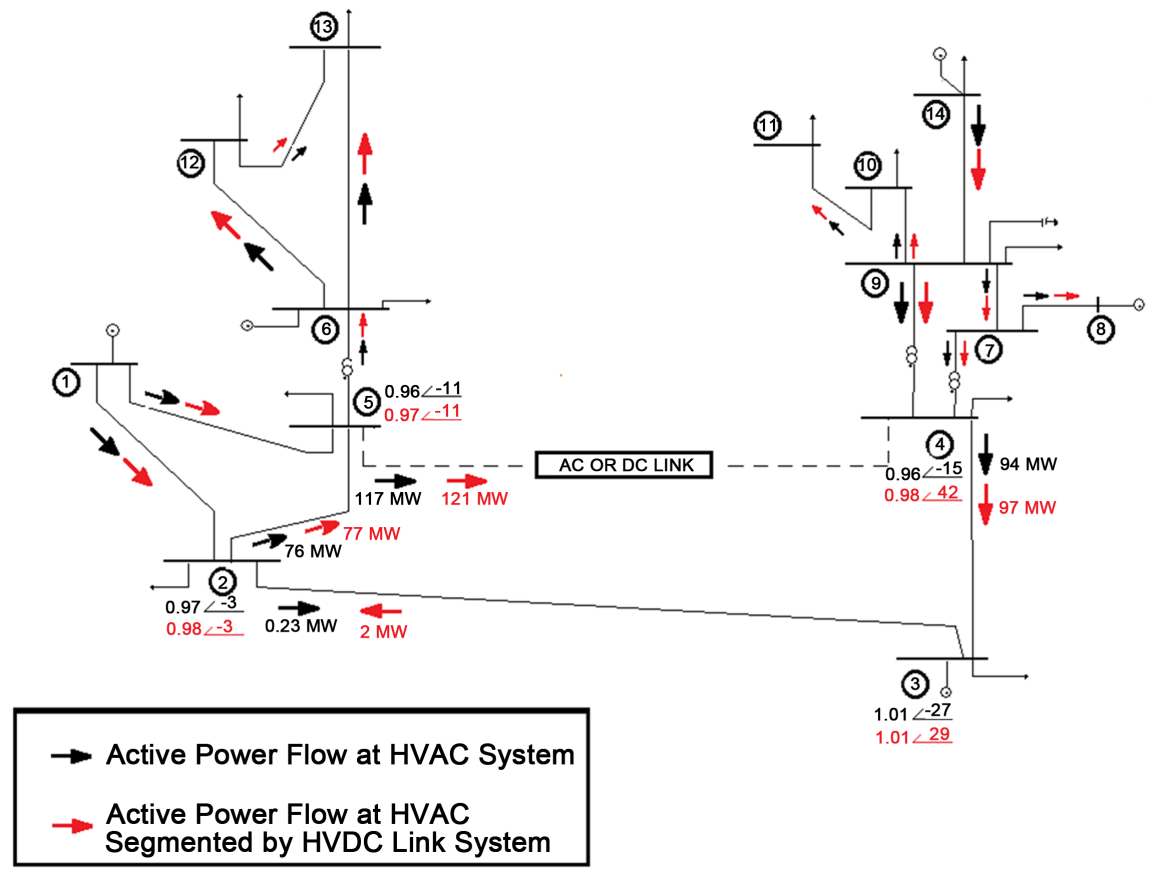

Figure 5. Active power flow diagram.

Table 1. Bus voltage, data from software ANAREDE.

\begin{tabular}{ccccc}
\hline \multirow{3}{*}{ Bus } & \multicolumn{2}{c}{ Voltage [p.u.] } & Angle $\left(^{\circ}\right)$ \\
\cline { 2 - 5 } & $\begin{array}{r}\text { HVAC } \\
\text { System }\end{array}$ & $\begin{array}{r}\text { HVAC Segmented by } \\
\text { HVDC Link System }\end{array}$ & $\begin{array}{c}\text { HVAC } \\
\text { System }\end{array}$ & $\begin{array}{c}\text { HVAC Segmented by } \\
\text { HVDC Link System }\end{array}$ \\
\hline $\mathbf{1}$ & 1.0000 & 1.0000 & 0 & 0.0000 \\
$\mathbf{2}$ & 0.9790 & 0.9803 & -3.419 & -3.3755 \\
$\mathbf{3}$ & 1.0100 & 1.0100 & -27.9442 & 29.7315 \\
$\mathbf{4}$ & 0.9651 & 0.9848 & -15.353 & 42.0371 \\
$\mathbf{5}$ & 0.9607 & 0.9709 & -11.8675 & -11.9682 \\
$\mathbf{6}$ & 1.0000 & 1.0000 & -16.2139 & -16.2688 \\
$\mathbf{7}$ & 0.9879 & 0.9968 & -12.6892 & 44.6146 \\
$\mathbf{8}$ & 1.0200 & 1.0200 & -12.6892 & 44.6146 \\
$\mathbf{9}$ & 0.9693 & 0.9779 & -11.2629 & 46.0105 \\
10 & 0.9584 & 0.9671 & -11.7653 & 45.517 \\
11 & 0.9517 & 0.9605 & -12.0948 & 45.1934 \\
$\mathbf{1 2}$ & 0.9862 & 0.9862 & -17.0279 & -17.0829 \\
$\mathbf{1 3}$ & 0.9842 & 0.9842 & -17.0045 & -17.0594 \\
$\mathbf{1 4}$ & 1.0200 & 1.0200 & 2.932 & 60.303 \\
\hline & & & & \\
\hline
\end{tabular}

necttion lines of the areas, lines 2 - 3 and 4 - 5. After insertion of the DC link at place of line $4-5$, the voltage reference of the area 2 is made only by line $2-3$. The angular openings in this line are very large at two cases, although the power flow are small due to the impedances used. 
One of the main causes of the abrupt change in the angles of the busbar voltages is the inversion of the active power flow in line 2 - 3. In the HVAC system, this line transmits $0.23 \mathrm{MW}$ from area 1 to area 2. In the segmented system, the HVDC link transmits 3.5 MW more to area 2 than line 4 - 5 of the HVAC system. So line 2-3 reverses the active power flow for system equalization. Figure 5 and Table 2 detail the active power flow for the test systems.

Table 2 also shows the active losses of the systems. The systems in their normal operation shows similar losses. Figure 6 and a Table 3 show the reactive power flow of the lines. All lines in both test systems exhibit inductive behavior, in other words, reactive energy consumption consumed by the line inductance is greater than a reactive energy generated in the line susceptance. The reactive power consumption in the circuits of the HVAC system segmented by HVDC is lower than the consumption in HVAC system. The HVDC segmented system has a higher reactive power generation to consumption at AC-DC converters, that can get to consumes the equivalent $60 \%$ of the active power transferred, as reported in [8].

Table 2. Active power flow anda active power losses, data from software ANAREDE.

\begin{tabular}{|c|c|c|c|c|c|c|}
\hline \multirow[b]{2}{*}{$\begin{array}{l}\text { From } \\
\text { Bus }\end{array}$} & \multirow[b]{2}{*}{$\begin{array}{l}\text { To } \\
\text { Bus }\end{array}$} & \multirow[b]{2}{*}{ Line } & \multicolumn{2}{|c|}{ Active Power Flow [MW] } & \multicolumn{2}{|c|}{ Active Power Losses [MW] } \\
\hline & & & $\begin{array}{l}\text { HVAC } \\
\text { System }\end{array}$ & $\begin{array}{c}\text { HVAC Segmented } \\
\text { by HVDC } \\
\text { Link System }\end{array}$ & $\begin{array}{l}\text { HVAC } \\
\text { System }\end{array}$ & $\begin{array}{c}\text { HVAC Segmented } \\
\text { by HVDC } \\
\text { Link System }\end{array}$ \\
\hline 1 & 2 & 1 & 100.4645 & 98.7955 & 1.9618 & 1.8944 \\
\hline 1 & 5 & 2 & 89.8082 & 90.4154 & 4.3718 & 4.4171 \\
\hline 2 & 3 & 3 & 0.2347 & -2.0459 & 0.0897 & 1.6118 \\
\hline 2 & 5 & 4 & 76.568 & 77.2478 & 3.53 & 3.6498 \\
\hline 3 & 4 & 5 & -94.055 & -97.8576 & 9.7113 & 9.203 \\
\hline 4 & 5 & 6 & -117.5181 & -121 & 2.3601 & 0.11 \\
\hline 4 & 7 & 7 & -21.6671 & -21.586 & 0 & 0 \\
\hline 4 & 9 & 8 & -12.3811 & -12.382 & 0 & 0 \\
\hline 5 & 6 & 9 & 30.9963 & 30.9963 & 0 & 0 \\
\hline 6 & 12 & 10 & 6.571 & 6.571 & 0.0594 & 0.0594 \\
\hline 6 & 13 & 11 & 13.2253 & 13.2253 & 0.1358 & 0.1358 \\
\hline 7 & 8 & 12 & 0 & 0 & 0 & 0 \\
\hline 7 & 9 & 13 & -21.6671 & -21.586 & 0 & 0 \\
\hline 9 & 10 & 14 & 12.5884 & 12.5869 & 0.0744 & 0.0731 \\
\hline 9 & 14 & 15 & -76.1367 & -76.0549 & 8.9633 & 9.0451 \\
\hline 10 & 11 & 16 & 3.514 & 3.5138 & 0.014 & 0.0138 \\
\hline 12 & 13 & 17 & 0.4116 & 0.4116 & 0.0011 & 0.0011 \\
\hline
\end{tabular}




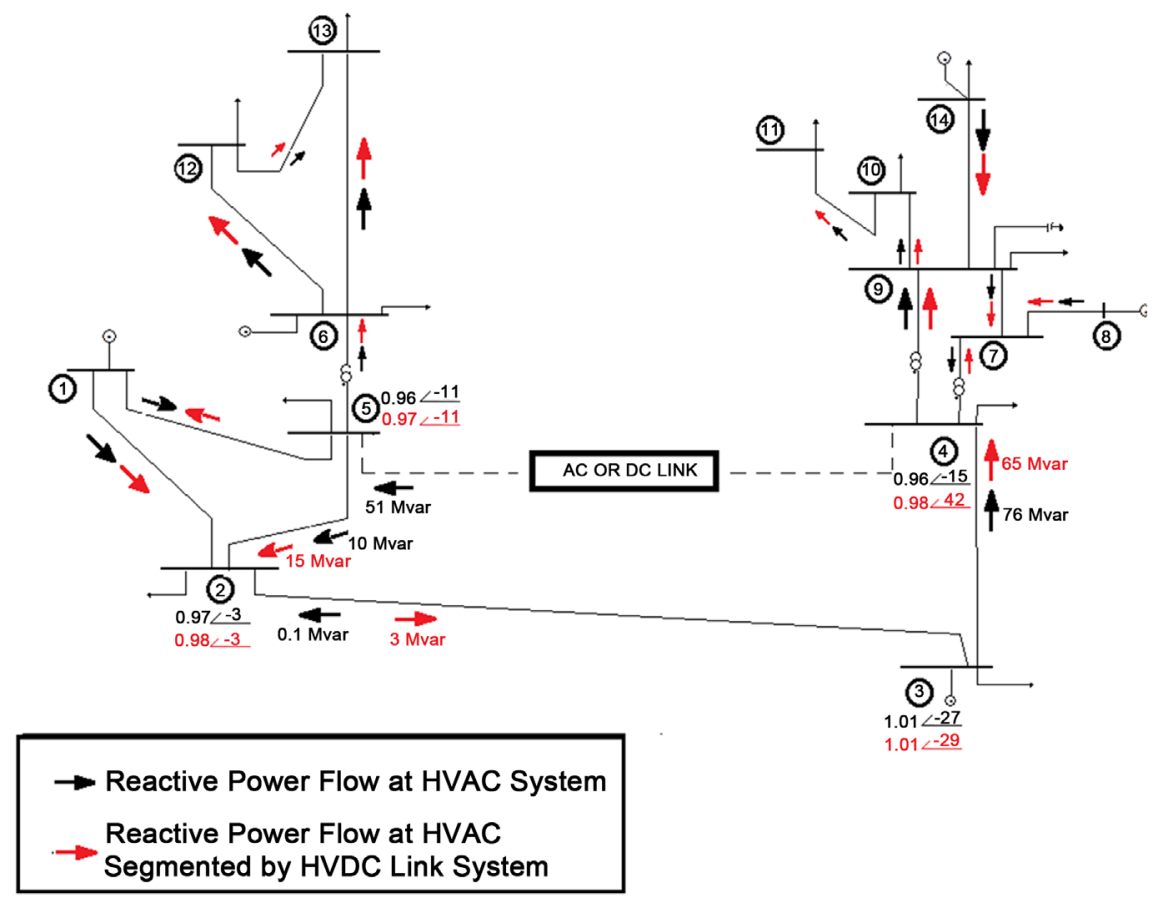

Figure 6. Reactive power flow diagram.

Table 3. Reactive power flow and reactive power consuming/generating.

\begin{tabular}{|c|c|c|c|c|c|c|}
\hline \multirow{2}{*}{$\begin{array}{l}\text { From } \\
\text { Bus }\end{array}$} & \multirow{2}{*}{$\begin{array}{l}\text { To } \\
\text { bus }\end{array}$} & \multirow{2}{*}{ Line } & \multicolumn{2}{|c|}{ Reactive Power Flow [MVAr] } & \multicolumn{2}{|c|}{$\begin{array}{c}\text { Reactive Power } \\
\text { Consuming/Generating [MVAr] }\end{array}$} \\
\hline & & & $\begin{array}{l}\text { HVAC } \\
\text { System }\end{array}$ & $\begin{array}{c}\text { HVAC Segmented } \\
\text { by HVDC Link System }\end{array}$ & $\begin{array}{l}\text { HVAC } \\
\text { System }\end{array}$ & $\begin{array}{l}\text { HVAC Segmented by } \\
\text { HVDC Link System }\end{array}$ \\
\hline 1 & 2 & 1 & 2.8190 & 1.1692 & 0.8192 & 0.6069 \\
\hline 1 & 5 & 2 & 2.6221 & -1.8378 & 13.3166 & 13.4555 \\
\hline 2 & 3 & 3 & -0.1758 & 3.3622 & 0.0897 & 1.6118 \\
\hline 2 & 5 & 4 & -10.5245 & -15.4996 & 7.5228 & 7.8503 \\
\hline 3 & 4 & 5 & 76.4009 & 65.9327 & 23.5372 & 22.2152 \\
\hline 4 & 5 & 6 & 51.5465 & - & 7.4446 & \\
\hline 4 & 7 & 7 & -0.0050 & 5.3502 & 1.0081 & 1.0200 \\
\hline 4 & 9 & 8 & 5.2222 & 7.4468 & 1.0123 & 1.1242 \\
\hline 5 & 6 & 9 & 13.7601 & 18.4002 & 2.7281 & 3.0177 \\
\hline 6 & 12 & 10 & 2.2761 & 2.2761 & 0.1237 & 0.1237 \\
\hline 6 & 13 & 11 & 5.5161 & 5.5161 & 0.2675 & 0.2675 \\
\hline 7 & 8 & 12 & -17.9907 & -13.1022 & 0.5842 & 0.3043 \\
\hline 7 & 9 & 13 & 16.9776 & 17.4323 & 0.8541 & 0.8523 \\
\hline 9 & 10 & 14 & 7.8305 & 7.8264 & 0.1977 & 0.1941 \\
\hline 9 & 14 & 15 & 28.7881 & 31.9464 & 19.0662 & 19.2402 \\
\hline 10 & 11 & 16 & 1.8328 & 1.8323 & 0.0328 & 0.0323 \\
\hline 12 & 13 & 17 & 0.5524 & 0.5524 & 0.0010 & 0.0010 \\
\hline
\end{tabular}




\subsection{Contingency-Loss of Generation of $70 \%$ in Area 2}

\subsubsection{Results for the HVAC Testing System}

The programmed contingency is the loss of $70 \%$ of the generation, that is, 70 MW of the generation of bus 14, which is contained in area 2. It will be considered that the generator of area 1 can supply the power demanded by the system because the equation load/generation must be balanced for the convergence of power flow, even in cases of contingency. Thus, the swing bus assumes all of the bus generation loss 14 .

The data shown in Figure 7 and Figure 8 illustrate the comparisons between

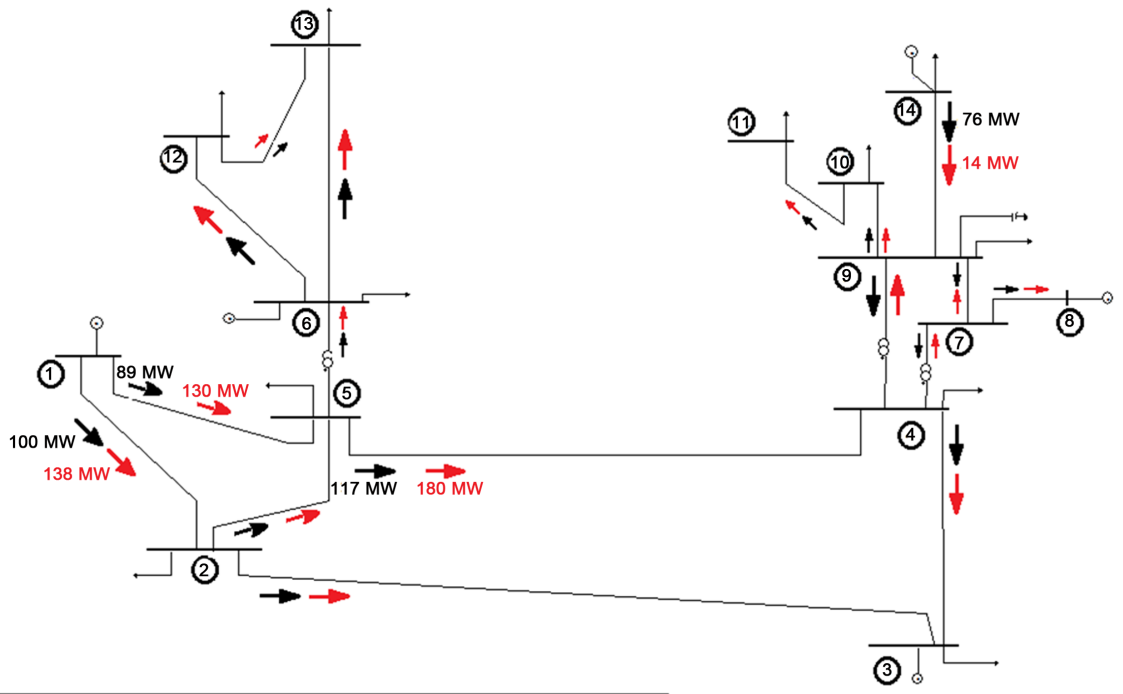

Active Power Flow at HVAC Normal System

Active Power Flow at HVAC

System at Contingency

Figure 7. Active power flow diagram at HVAC system.

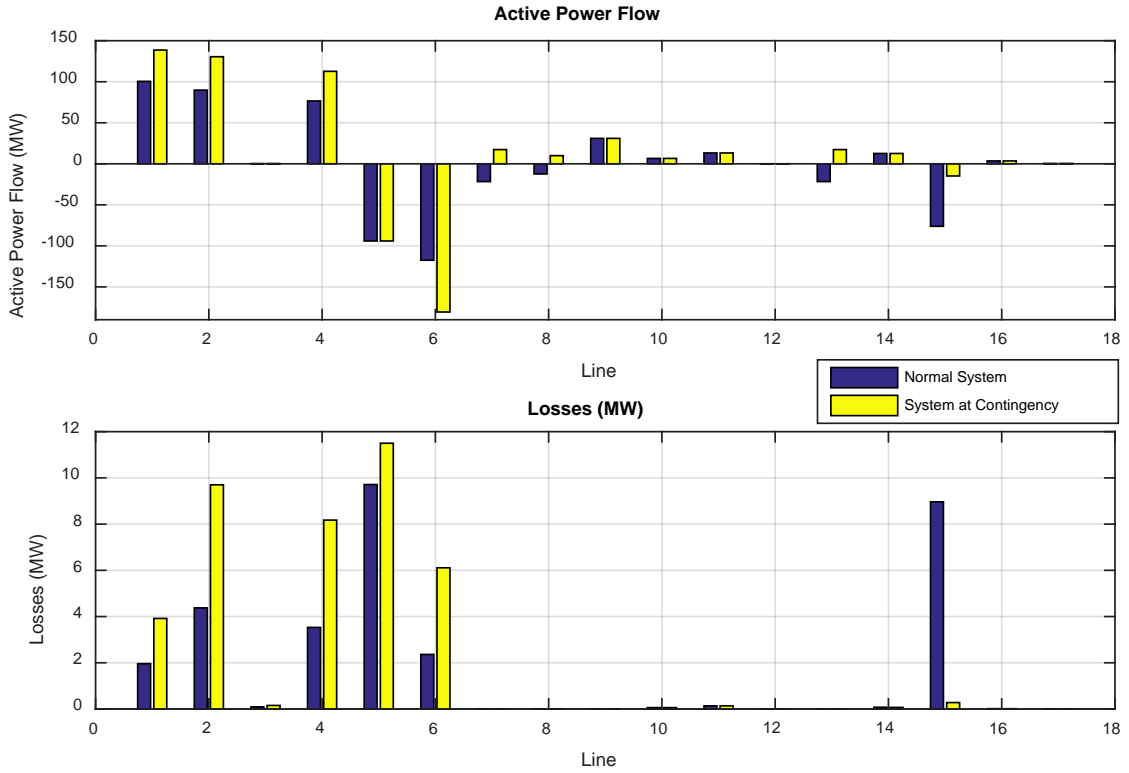

Figure 8. Active power flow and losses at HVAC system. 
flows and losses in the serial elements of the systems. Lines 1, 2, 4, 5 and 6 are the lines closest to the generator of area 1 , so these lines are the most overloaded during the contingency. The active power flow in lines 1, 2 and 6 increased 37\%, $45 \%$ and $53 \%$ respectively, In [2], the results are similar, with the flows exceeding line ratings by 20 to $40 \%$. Considering this significant increase, these lines run the risk of being shut down by overcurrent protections, worsening the contingency or causing the collapse of the entire system. There were three reversals of flow direction and considerable increases in losses. Highlight for Line 15, which reduced its losses because it stopped transferring energy from the generator of area 2 . The active losses in the lines and transformers increased by $81.45 \%$ during the contingency.

Another critical point to be analyzed is the bus voltages. The bus data are shown in Figure 9. The buses that showed the highest voltage during the contingency are in area 2, in the surroundings of the generator bus that in the contingency reduced its generation drastically, consequently, it reduced the losses and therefore raised the voltages in the buses. It is observed, analyzing Figure 9, that there was a redistribution of reactive power in the system. This redistribution caused the system to operate under better voltage conditions in the buses of area 2, while in area 1 the tensions worsened. Reference [2] also have voltage drops due the increase of the line power flows. The system also increased reactive power generation in an attempt to maintain stable bus voltages.

\subsubsection{Results for the Tests of a HVCA Segmented by HVDC System}

The HVDC link isolates areas 1 and 2 transmitting the constant power of 121 MW. Thus, the energy generated in area 1 is not transmitted to area 2 and the load/generation equation is unbalanced. Consequently there is no convergence of the power flow to the system. The load relief in area 2 is used in this case for
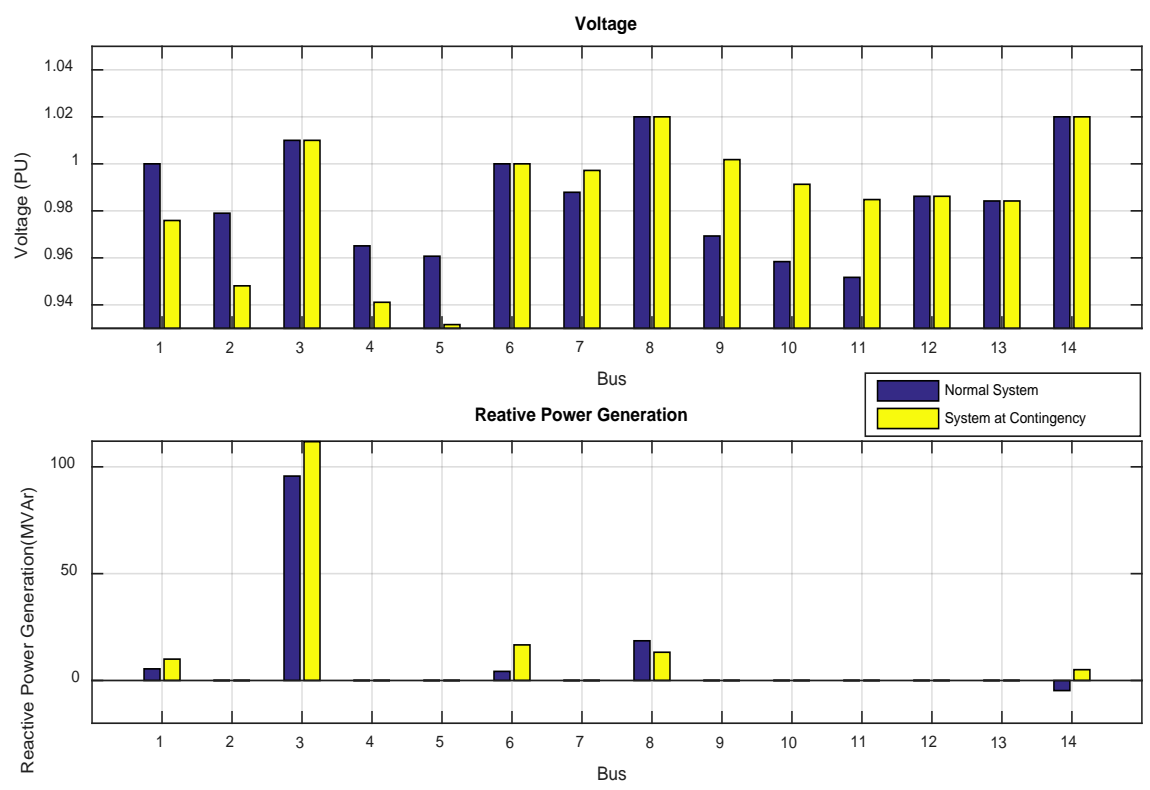

Figure 9. Voltage and reactive power generation at HVAC system. 
the convergence of the power flow. Thus, the simulated contingency will be the loss generation of $70 \mathrm{MW}$ in bus 14 and the $50 \mathrm{MW}$ load relief in bus 3, both buses belonging to area 2 .

Figure 10 and Figure 11 detail the power flow and active loss values per line. As in [2], the power flows did not exceed the line ratings in the sector adjacent to the sector with loss of generation, the power flow of the lines belonging to the area 1, practically did not change. Already the power flow of some lines of area 2 were redirected due to loss of generation in bus 14 . The losses of the lines had almost no changes except for lines 5 and 15 . Line 5 is connected to bus 3 , which suffered Load relief, reducing the power flow in their lines and consequently the losses. The line 15 is connected to the bus 14 which has lost generation and

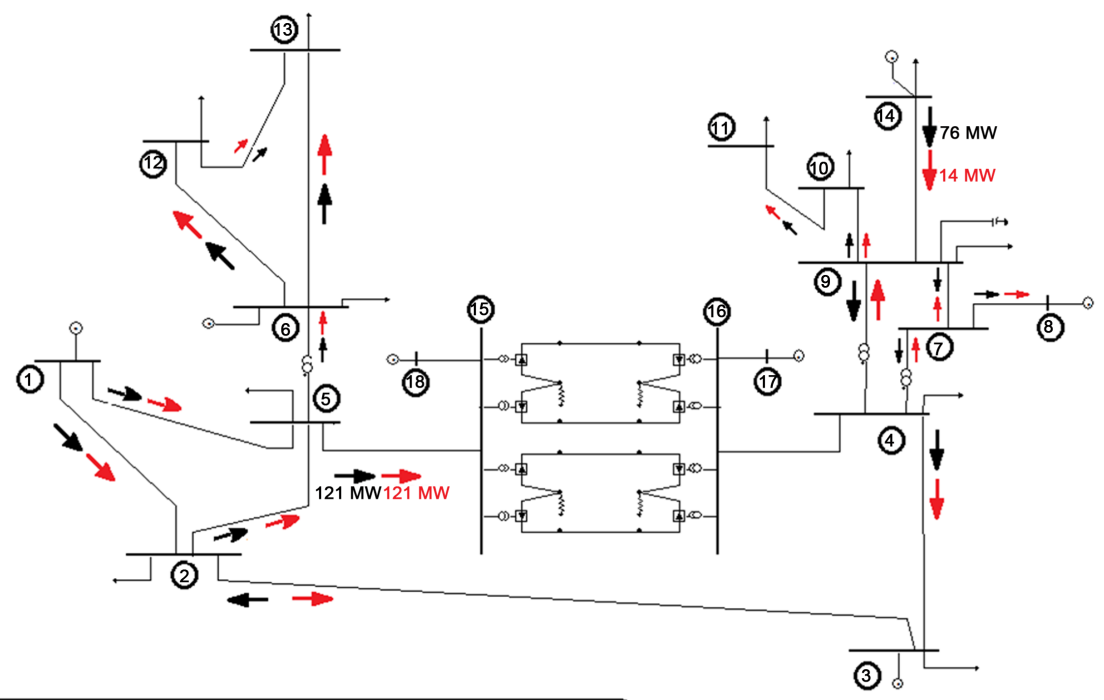

Active Power Flow at HVAC System by HVDC Link Normal System Active Power Flow at HVAC Segmented by HVDC Link System at Contingency

Figure 10. Active power flow diagram at HVAC segmented by HVDC link system.

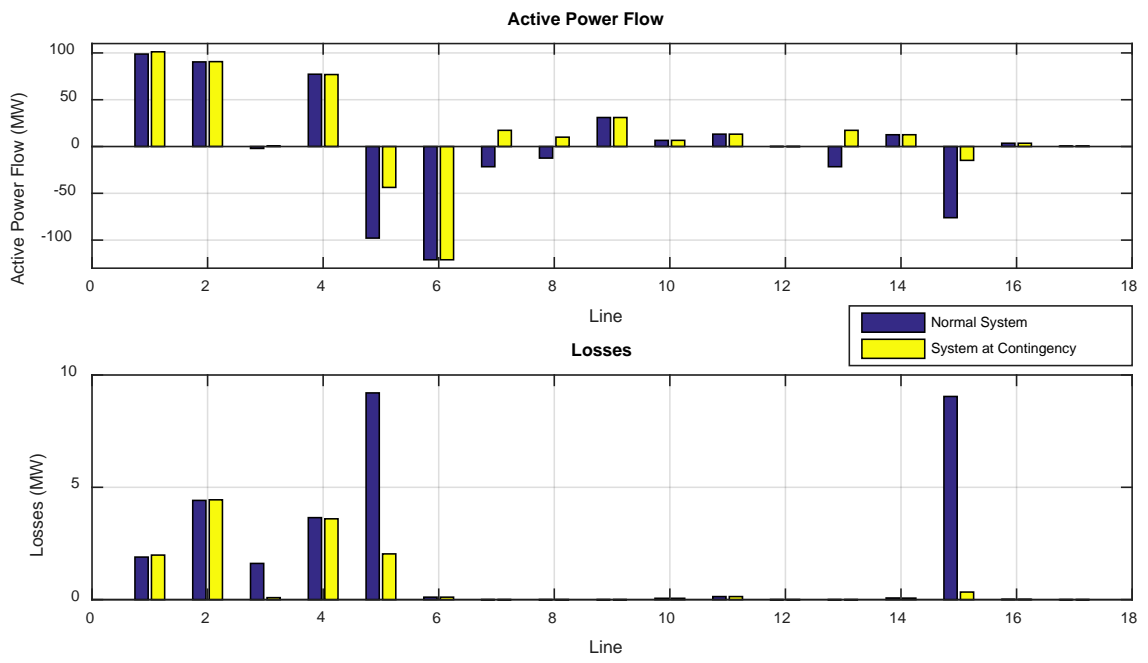

Figure 11. Active power flow diagram at HVAC segmented by HVDC link system. 
started to transmit a smaller amount of energy to the system reducing the losses in the line.

The operating voltage of the buses and the reactive power generation per bus is shown in Figure 12. The voltages of the buses in area 1 are practically the same in both situations. The voltages of the buses of area 2 during the contingency improved with respect to the initial system, due to the load of the lines that diminished and to the relief of load. In [2], the results are similar and some voltage dynamic are presented. The so-called buses 15 and 16 are the system interface buses with the HVDC link and the buses 17 and 18 are the buses that connect the synchronous compensators of the HVDC link to the interface buses. Bus 18 is the largest supplier of reactive power for the system. With load relief, during contingency, the reactive power generation of the overall system decreases.

\section{Conclusions}

This paper proposes to study the effect of DC segmentation towards a contingency that would initiate great scale interruption. Simulations were performed with HVAC test systems and HVAC system segmented by HVDC.

For the HVAC system, if area 1 was already generating at or near of the generation limit, the system would collapse due to under voltage and under frequency, since it would not be able to supply the demand of all system. From the data obtained from the simulations and considering the hypothesis that the generators of area 1 can supply the power demanded by the system, it can be concluded that possibly the whole HVAC system would suffer a blackout initiated by the generation contingency in area 2 . Therefore, under both conditions, we would have to shut down the entire system.
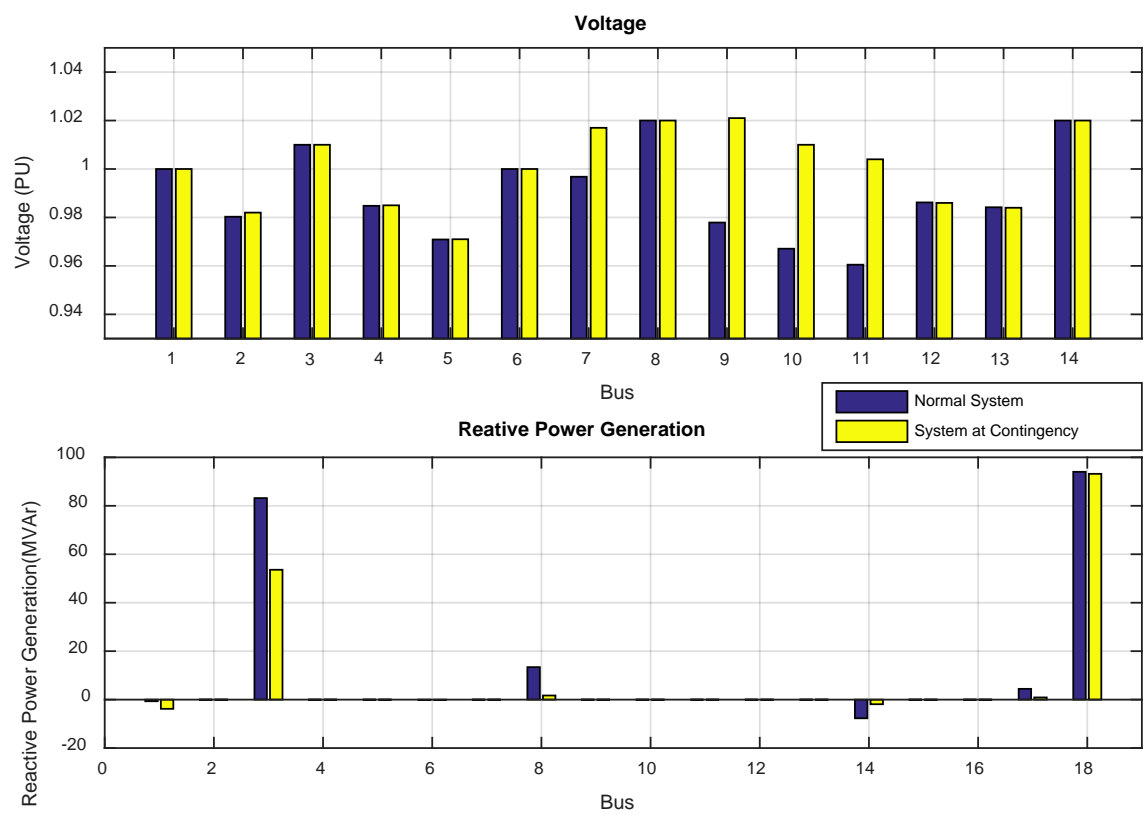

Figure 12. Voltage and reactive power generation at HVAC segmented by HVDC link system. 
Through the simulation, for the HVAC system segmented by the HVDC link, it can be concluded that area 1 was not affected by the contingency. The simulations performed without load relief did not converge, indicating that area 2 could not be maintained, being de-energized without necessarily provoking disturbances in area 1 .

By this study, it is concluded that segmentation of large AC networks through DC links improves the reliability of the network and increases the capacity of transfer of energy. The possibility for further studies can be proposed by new configurations of the grid segmentation to assess a better place to DC link or economic analysis of the benefit-cost to implement a grid segmentation.

\section{References}

[1] Mousavi, O.A., Bizumic, L. and Cherkaoui, L. (2013) Assessment of HVDC Grid Segmentation for Reducing the Risk of Cascading Outages and Blackouts. 2013 IREP Symposium-Bulk Power System Dynamics and Control-IX (IREP), Rethymnon, 25-30 August 2013.

[2] Clark, H., Edris, A.A., El-Gasseir, M.M., Epp, K., Isaacs, A. and Woodford, D. (2008) Softening the Blow of Disturbances-Segmentation with Grid Shock Absorbers for Reliability of Large Transmission Interconnections. IEEE Power \& Energy Magazine, 6, 30-41. https://doi.org/10.1109/MPAE.2008.4412938

[3] Bahrman, M.P. and Johnson, B.K. (2007) The ABCs of HVDC Transmission Technologies-An Overview of High Voltage Direct Current Systems and Applications. IEEE Power \& Energy Magazine, 3, 32-44. https://doi.org/10.1109/MPAE.2007.329194

[4] Ye, P., Sui, Y.Q., Yuan, Y.H., Li, X.M. and Tao, J.Q. (2010) Transient Stability Analysis of Hu-Liao HVDC and AC Parallel Transmission System. Smart Grid and Renewable Energy, 1, 74-80. https://doi.org/10.4236/sgre.2010.12012

[5] Hong, Y.D. and Yu, T. (2013) Reliability Improvement Strategies for HVDC Transmission System. Energy and Power Engineering, 5, 52-56.

https://doi.org/10.4236/epe.2013.53B011

[6] Loehr, G.C. (2007) Enhancing the Grid, Smaller Can Be Better. Energybiz Magazine, 35-36.

[7] Clark, H.K., El-Gasseir, M.M., Epp, H.D.K. and Edris, A.A. (2008) The Application of Segmentation and Grid Shock Absorber Concept for Reliable Power Grids. Power System Conference, MEPCON2008, 12 th International Middle-East, 34-38. https://doi.org/10.1109/MEPCON.2008.4562303

[8] Kim, C.-K., Kim, J.-Y., Lee, S.-D. and Sim, E.-B. (2011) Stability Enhancement in HVDC System with STATCOM. Engineering, 3, 1072-1081.

https://doi.org/10.4236/eng.2011.311133 
Submit or recommend next manuscript to SCIRP and we will provide best service for you:

Accepting pre-submission inquiries through Email, Facebook, LinkedIn, Twitter, etc. A wide selection of journals (inclusive of 9 subjects, more than 200 journals)

Providing 24-hour high-quality service

User-friendly online submission system

Fair and swift peer-review system

Efficient typesetting and proofreading procedure

Display of the result of downloads and visits, as well as the number of cited articles Maximum dissemination of your research work

Submit your manuscript at: http://papersubmission.scirp.org/

Or contact jpee@scirp.org 